Vol. 11 (2002): 13-24.

\title{
Fluid milk consumption and demand response to advertising for non-alcoholic beverages
}

Kyrre Rickertsen

Agricultural University of Norway, Department of Economics and Social Sciences, PO Box 5033, N-1432 Ås, Norway and Norwegian Agricultural Economics Research Institute, PO Box 8024 Dep., N-0030 Oslo, Norway, e-mail: kyrre.rickertsen@ios.nlh.no

Geir Wæhler Gustavsen

Norwegian Agricultural Economics Research Institute, PO Box 8024 Dep., N-0030 Oslo, Norway, e-mail: geir.gustavsen@nilf.no

\begin{abstract}
Norwegian fluid milk consumption has declined steadily over the last twenty years, despite the dairy industry spending increasing amounts of money on advertising. Using a two-stage model, we investigate whether advertising has increased the demand for milk. No effect of advertising on the demand for non-alcoholic beverages is found in the first stage. In the second stage, an almost ideal demand system including advertising expenditures on competing beverages is estimated. The effects of generic advertising within the beverage group are positive and significant for whole milk and negative and significant for lower fat milk. The own-advertising elasticity for the combined fluid milk group is 0.0008 . This highly inelastic elasticity suggests that increased advertising will not be profitable for the producers. Several cross-advertising effects are statistically significant, emphasizing the usefulness of a demand system approach.
\end{abstract}

Key words: advertising, almost ideal demand system, milk, Norway

\section{Introduction}

Norwegians consume large quantities of fluid milk, however, the consumption has declined steadily over the last twenty years. The per capita consumption decreased by about 20 percent over the 1975 to 1995 period. Moreover, the composition of consumption has changed substantially after the introduction of low fat milk
(1.5 percent fat) in 1985 . The annual per capita consumption of lower fat (nonfat and low fat) milk has increased from 19 to 100 liters, while the whole milk consumption has dropped from 127 to 33 liters since 1985 . The purchasing pattern of other beverages has also changed. The per capita consumption of hot drinks (coffee, tea, and cocoa) declined by more than 20 percent during the period, and the consumption of cold beverages (fruit juices, soft drinks, light beer, 
Rickertsen, K. \& Gustavsen, G.W. Milk consumption and demand response to advertising

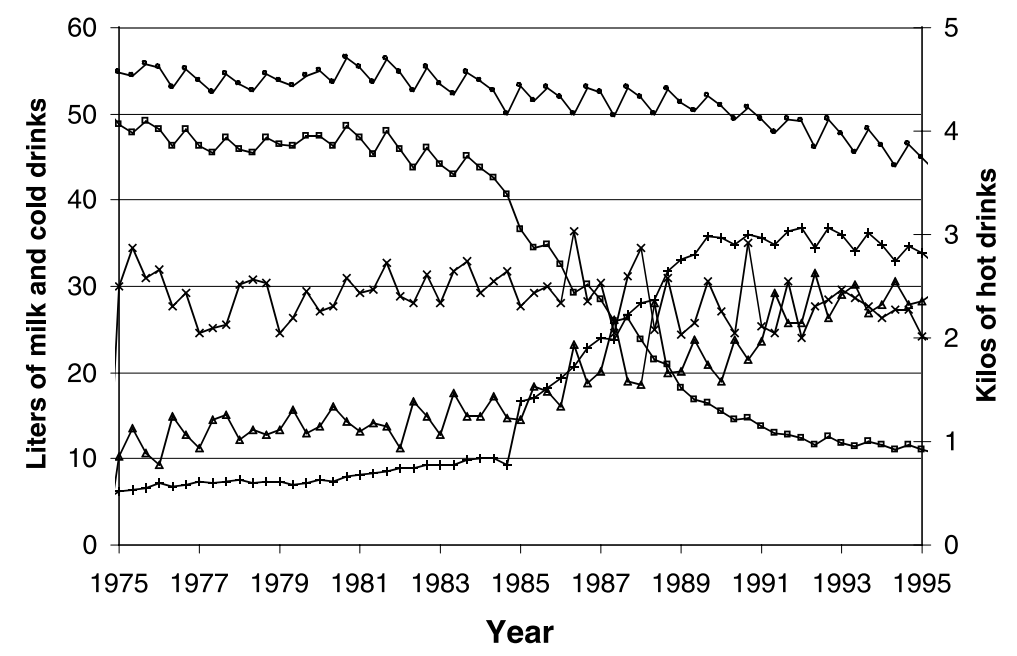

$\rightarrow$ Fluid milk $\rightarrow$ Whole milk $\rightarrow$ Lower fat milk $\rightarrow$ Cold drinks $\rightarrow$ Hot drinks
Fig. 1. Per capita consumption of non-alcoholic beverages (Sources: Norwegian Dairy Cooperative and Norwegian Social Science Data Service). and mineral water) more than doubled. The changes in consumption are shown in Fig. 1. In this figure, and in this study, the prices and quantities are based on four-month intervals. We use a four-month observation period instead of the commonly used three-month observation period (quarterly data) because the Norwegian Dairy Cooperative (Norske Meierier) uses a fourmonthly reporting period.

We also observe similar changes in the consumption of beverages in other countries. The US per capita consumption of soft drinks has, for example, increased by 111 percent between 1970 and 1995 while the fluid milk consumption declined by 22 percent (Putnam and Allshouse 1997). The US trend is also toward lower fat milk. The consumption of whole milk was cut by two-thirds between 1970 and 1997 while the use of lower fat milk nearly tripled (Putnam and Allshouse 1998).

The decline in milk consumption causes concern in the dairy industry and it is of considerable interest to investigate to what extent the observed changes can be explained by factors the dairy industry itself can influence, such as changes in advertising. The Norwegian Dairy Cooperative's advertising expenses on fluid milk increased from about NOK 1.3 million in 1975 to about 20 million (approximately US $\$ 2.2$ million) by the end of the period. This is a substantial increase in real terms, since the consumer price index (CPI) quadrupled over the period. However, the expenses are fairly small compared with advertising for cold drinks (NOK 119 million in 1995) and hot drinks (NOK 55 million in 1995). The milk advertising has been directed toward increasing the total sales of fresh milk. The advertising for cold and hot drinks is, by contrast, branded. Brand advertising may both increase aggregate demand for, for example, cold drinks and reallocate market shares among the various brands of cold drinks. This advertising may also reduce the demand for fluid milk over time. Annual current advertising expenditures and the CPI are reported in Fig. 2.

There has been a considerable research activity on the effects of generic advertising on the demand for fluid milk; see, for example, Johnson et al. (1992) and Forker and Ward (1993) for summaries of some results. Recent studies include Suzuki et al. (1994), Reberte et al. (1996), Kaiser (1997), Suzuki and Kaiser (1997), Lenz et al. (1998), Pritchett et al. (1998), Kamp and Kaiser (1999), Tomek and Kaiser (1999), Chung and Kaiser (1999), and Kinnucan (1999). These studies have found a positive, and usual- 
Vol. 11 (2002): 13-24.

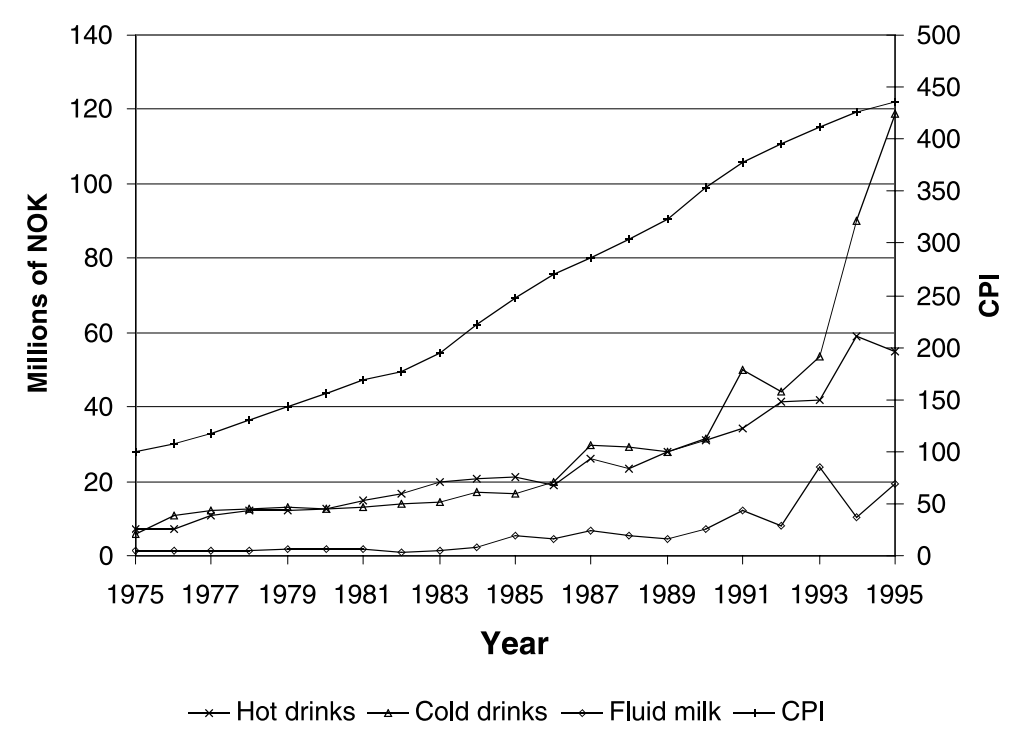

Fig. 2. Advertising expenditures for non-alcoholic beverages and the consumer price index (Sources: ACNielsen and Statistics Norway). ly significant and substantial, effect of generic advertising for milk on demand for milk. However, the results were obtained using a singleequation framework, which neglects advertising expenditures on substitutes for fluid milk. Goddard et al. (1992) and Kinnucan et al. (2001) used demand systems and found positive but small own-advertising elasticities for fluid milk in Canada and the United States. A demand system allows for cross-commodity advertising effects on competing goods. As advertising expenditures for the various types of non-alcoholic beverages increase, it is not clear to what extent the advertising efforts add to overall non-alcoholic beverage demand or merely cause substitution among beverages. If substitution is important, the effects of milk advertising are better studied in a model incorporating advertising for other close substitutes.

Given consumers' concerns about fat and cholesterol in food and beverages, it is questionable to aggregate the various types of fluid milk. Nevertheless, fluid milk is usually treated as one beverage when the effects of advertising are studied. One exception is Kaiser and Reberte (1996) who concluded that advertising had a positive and equal impact on the demand for whole, low fat, and nonfat milks. We divide fluid milk into two groups, whole and lower fat milk, to detect any differences in sales responsiveness to advertising.

The contributions of this paper are as follows. First, to fix ideas the Norwegian milk market is discussed graphically. Second, a demand system framework is utilized to take substitution effects of advertising into account. Third, fluid milk is divided into whole and lower fat milk to study possible differences in advertising responsiveness. Finally, we discuss whether the advertising causes producer revenue, net of advertising cost, to increase.

\section{Graphical analysis}

Even though the government has allowed some competition in the fluid milk market during the last few years, the dairy cooperative was a monopolist during the period of study. Fig. 3 can illustrate this market. We abstract from the marketing channel and the possibility for price-discrimination schemes between fresh and industrially processed milk. Norway is a small-country exporter that can sell excess supply to the 
Rickertsen, K. \& Gustavsen, G.W. Milk consumption and demand response to advertising

world market at the price $P_{1}$. At the domestic market the dairy cooperative is a monopolist. Let the domestic demand curve be illustrated by $D$, the supply curve by $S$, and the marginal revenue curve by $M R$. If the cooperative was allowed to determine the domestic consumer price, it would set the price to $P_{0}$, the quantity $Q_{0}$ would be sold domestically, and the quantity $\left(Q_{1}-Q_{0}\right)$ would be exported. However, the government regulates the monopoly by setting the consumer price to $P_{2}$. To reduce the production they also use nontradable and historically based production quotas represented by $S^{*}$ in the figure. The quota is set larger than the domestic demand at price $P_{2}$ resulting in sales of the quantity $Q_{2}$ domestically and export of the quantity $\left(Q_{3}-Q_{2}\right)$.

Advertising may shift the domestic demand curve. Assuming successful advertising, the demand curve shifts to $D^{*}$ and exports are eliminated as in the figure. The dairy cooperative is not allowed to increase the price of milk to finance advertising, which has to be financed by transfers within the organization. Advertising has increased the producer surplus with the hatched area $a b c d$. If this increase in producer surplus is larger than the direct costs of advertising plus

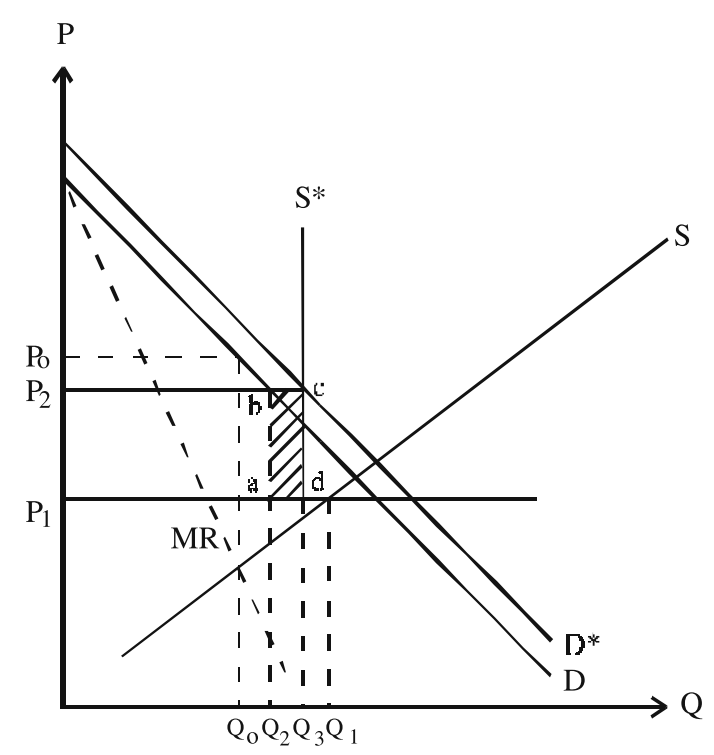

Fig. 3. Advertising in the Norwegian milk market. the opportunity cost of the capital spent on advertising, the advertising has been profitable for the producers. The change in producer surplus can be calculated as $\left(P_{2}-P_{1}\right) \cdot\left(Q_{3}-Q_{2}\right)$.

The effects of advertising in the market described above are different than in the markets described in Kinnucan and Myrland (2001). They describe markets where prices are determined under free-market conditions and the law-of-oneprice holds. Our market is closer to the supplymanaged markets discussed in Kinnucan (1999); however, we have exogenously set prices in combination with a quota that is larger than the domestic demand.

\section{Demand models with advertising effects}

We follow Goddard and Amuah (1989), Richards et al. (1997), and Kinnucan et al. (2001) and estimate a two-stage model. In the first stage, the consumer allocates the total expenditure to broad commodity groups, such as non-alcoholic beverages. In the second stage, the total expenditures on non-alcoholic beverages are divided among the individual drinks. Richards et al. (1997) adhered to the theoretical requirements of two-stage budgeting and used the linear expenditure system in the first stage and the almost ideal demand system in the second stage. This approach is, in many ways, desirable and allows the estimation of demand elasticities satisfying the basic properties of demand (homogeneity, symmetry, and adding-up) at both stages. However, we do not use a demand system in stage one because we have no data for the advertising expenditures for goods other than nonalcoholic beverages.

In the first stage, we start with a double-log demand function

(1) $\ln q_{i}=\theta_{i}+E_{i} \ln x+\sum_{j=1}^{n} e_{i j} \ln p_{j}$,

where $q_{i}$ is per capita consumption of $\operatorname{good} i$ (in our case non-alcoholic beverages), $x$ is per cap- 
Vol. 11 (2002): 13-24.

ita total expenditure, $p_{j}$ is the nominal price of $\operatorname{good} j, E_{i}$ is the expenditure elasticity, and $e_{i j}$ is the uncompensated price elasticity for good $i$ with respect to the price of $\operatorname{good} j$. The general relationship between the uncompensated and compensated price elasticities, $e_{i j}{ }^{*}$ is $e_{i j}=e_{i j}{ }^{*}-$ $w_{j} E_{i}$, where $w_{j}$ denotes the expenditure share of good $j$. Substituting this relationship into equation (1) yields

$$
\ln q_{i}=\theta_{i}+E_{i}\left(\ln x-\sum_{j=1}^{n} w_{j} \ln p_{j}\right)+\sum_{j=1}^{n} e_{i j}^{*} \ln p_{j}
$$

The index $\Sigma_{j} w_{j} \ln p_{j}$ is Stone's price index. Moschini (1995) showed that this index is not invariant to changes in the units of measurement. To avoid this potentially serious problem, we use the average expenditure share for each good in the index.

We include an advertising variable, $a d v$, to capture the possible effects of advertising expenditure on the demand for non-alcoholic beverages. The current expenditures are deflated with Stone's index, which is a part of the double-log model (2) and closely related to the almost ideal model that is used in the second stage. Seasonality in consumption has proved to be important in numerous studies of consumer demand and it is reasonable to believe that the consumption of beverages is higher during the summer months than in the rest of the year. Consequently, two seasonal dummy variables, $D_{2}$ and $D_{3}$, which are set to one in the second and third four-month periods, respectively, are included. Other factors of potential importance for demand have also changed. Kinnucan et al. (2001) found that age structure and incidence of dining out had significant effects on milk consumption. Factors such as health information or the introduction of new non-alcoholic beverages may also have affected the consumption. The best way to capture non-economic effects is to include variables closely related to the effects. However, the inclusion of several non-economic variables requires many degrees of freedom and, moreover, we do not have data for these variables. To approximate the total effect of these changes, a trend, $t$, is introduced and equation (2) is extended to

$$
\text { (3) } \begin{aligned}
\ln q_{i}= & \theta_{i}+\dot{E}_{i}\left(\ln x-\sum_{j=1}^{n} w_{j} \ln p_{j}\right)+\sum_{j=1}^{n} e_{i j}^{*} \ln p_{j} \\
& +a_{i}\left(\ln a d v_{i}-\sum_{j=1}^{n} w_{j} \ln p_{j}\right)+ \\
& \omega_{1} \ln t+\omega_{2} D_{2}+\omega_{3} D_{3},
\end{aligned}
$$

where $a_{i}$ denotes the own-advertising elasticity. Homogeneity of degree zero in prices and total expenditure implies that $\Sigma_{j} e_{i j}{ }^{*}=0$ and we impose this restriction.

Deaton and Muellbauer's (1980) almost ideal demand system is used in the second stage. The $i$-th good's expenditure share is given by

(4) $w_{i}=\alpha_{i}+\sum_{j=1}^{n} \gamma_{i j} \ln p_{j}+\beta_{i}[\ln x-\ln P]$,

where the price index, $\ln P$, is defined by

$$
\text { (5) } \begin{aligned}
\ln P= & \alpha_{0}+\sum_{k=1}^{n} \alpha_{k} \ln p_{k}+ \\
& \frac{1}{2} \sum_{k=1}^{n} \sum_{j=1}^{n} \gamma_{j k} \ln p_{k} \ln p_{j},
\end{aligned}
$$

and the other variables are defined as in the first stage.

The price and expenditure elasticities are calculated as

$$
\begin{aligned}
& e_{i j}=-\delta_{i j}+\frac{\gamma_{i j}}{w_{i}}-\frac{\beta_{i}}{w_{i}}\left(\alpha_{j}+\sum_{k=1}^{n} \gamma_{k j} \ln p_{k}\right) \\
& \text { and } E_{i}=1+\frac{\beta_{i}}{w_{i}}
\end{aligned}
$$

where $\delta_{i j}$ is the Kronecker delta $\left(\delta_{i j}=1\right.$ for $i=j$, and $\delta_{i j}=0$ for $\left.i \neq j\right)$. The demand restrictions, $\Sigma_{i} \alpha_{i}$ $=1, \Sigma_{i} \gamma_{i j}=\Sigma_{i} \beta_{i}=0$ (adding up); $\Sigma_{j} \gamma_{i j}=0$ (homogeneity); and $\gamma_{i j}=\gamma_{j i}$ (symmetry), are imposed on the system.

As in the first stage, two seasonal dummy variables and a trend variable are included. Furthermore, a dummy variable, low, is included to take account of the introduction of low fat milk in 1985. This dummy variable is allowed to interact with the trend, but not with advertising, price, or total expenditure, to save degrees of freedom.

Lee and Brown (1992) claim that, for commodities consumed daily, such as milk, it is difficult to argue that people need more than a few 


\section{Rickertsen, K. \& Gustavsen, G.W. Milk consumption and demand response to advertising}

months to purchase the product. Consequently, it is hard to argue for any carryover effect using a longer data interval. In agreement with their point of view, we introduce the vector of current period's advertising expenditures in each demand equation. The advertising expenditures are deflated with the modified Stone index as in the first-stage model. The demand shifters are introduced as modifiers of the intercepts in equations (4), (5), and (6), such that

$$
\begin{aligned}
\alpha_{i}= & \alpha_{i 0}+\alpha_{i 1} \operatorname{low}+\alpha_{i 2} t+\alpha_{i 3} l o w \cdot t+ \\
& \sum_{j=1}^{n} \phi_{i j}\left(\ln a d v_{j}-\sum_{j=1}^{n} w_{j} \ln p_{j}\right)+\sum_{m=2}^{3} \psi_{i m} D_{m} .
\end{aligned}
$$

The adding-up property implies that $\Sigma_{i} \alpha_{i 0}=$ $1, \Sigma_{i} \alpha_{i 1}=\Sigma_{i} \alpha_{i 2}=\Sigma_{i} \alpha_{i 3}=\Sigma_{i} \phi_{i j}=\Sigma_{i} \psi_{i m}=0$. The advertising elasticities, $a_{i j}$, are derived in Appendix 1 and calculated as

$$
a_{i j}=\frac{1}{w_{i}}\left(\phi_{i j}-\beta_{i} \sum_{k=1}^{n} \phi_{k j} \ln p_{k}\right) .
$$

The price, total expenditure, and advertising elasticities in the second stage (6) and (8) are conditional on the total expenditures allocated to non-alcoholic beverages in stage one. Carpentier and Guyomard (2001) provide formulas for approximating the unconditional price and expenditure elasticities from the estimated conditional elasticities; however, we did not pursue their approach. We only note that if the advertising elasticity in stage one is zero, the unconditional and conditional elasticities are numerically identical.

\section{Data and empirical implementation}

Prices for non-alcoholic beverages, alcoholic beverages, food, and other non-durables and services are included in the demand function at stage one. Furthermore, advertising expenditures for non-alcoholic beverages and total expendi- tures on non-durables and services are added as independent variables. The data on prices and the total expenditures were provided by Statistics Norway.

Four groups of beverages are specified at stage two: whole milk, lower fat milk, hot drinks, and cold drinks. The lower fat milk group consists of nonfat and low fat milk. The cold drinks group consists of fruit juices, soft drinks, light beer, and mineral water. The hot drinks group consists of coffee, tea, and cocoa. The prices and quantities of dairy products were obtained from the Norwegian Dairy Cooperative while the corresponding data for various hot and cold drinks were obtained from the Norwegian Social Science Data Services. The price and quantity observations are four-month data spanning the 1975 to 1995 period, which includes 63 observations. The prices of the elementary beverages were aggregated as Divisia price indices.

ACNielsen collected the advertising data. The data set was checked against available marketing data from the dairy cooperative, and the correspondence was good. The data cover advertising in newspapers, TV, radio, movies, and boards. Unfortunately, the advertising expenditures are only available on an annual basis. The expenditures were divided by three to calculate advertising expenditures in each four-month period. Possible fluctuations are smoothed away by this procedure. If there were substantial variations in the advertising activities throughout the year, the smoothing may bias our results. We discussed possible distributions of the advertising expenditures with our contact group in the dairy cooperative; however, they could not suggest any better distribution indicating that no pulsing strategy has been used in advertising milk. Therefore, we believe that a uniform distribution of advertising expenditures over the year is a reasonably good approximation. Fluid milk is mainly advertised as one good and the same advertising variable was used for lower fat and whole milk.

As discussed in the graphical analysis, we treat milk price as exogenous. The prices of hot drinks and in some cases cold drinks are deter- 
Vol. 11 (2002): 13-24.

mined at the world market and these prices are also treated as exogenous. Furthermore, work by Bronsard and Salvas-Bronsard (1984) suggests that price endogeneity is relatively unimportant in demand-system estimation when the goods in question represents a small share of income, as is the case for non-alcoholic beverages. Advertising expenditures and total non-alcoholic expenditures are also treated as exogenous as in most previous studies. The first-stage model (3) was estimated by ordinary least squares. The LSQ procedure in the TSP program was used to compute iterative seemingly unrelated regressions in stage two. As is customary, one equation was dropped from estimation.

Autocorrelation is frequently a serious problem in studies using time-series data. In the second stage, it was tested for by using first- and third-order Breusch-Godfrey tests. These tests are calculated as

(9)

$$
\begin{aligned}
& \hat{u}_{i, t}=\mathbf{x}_{\mathrm{t}}^{\prime} \beta+\rho \hat{u}_{i, t-1}+v_{i, t} \text { and } \\
& \hat{u}_{i, t}=\mathbf{x}_{\mathbf{t}}^{\prime} \beta+\rho_{1} \hat{u}_{i, t-1}+\rho_{2} \hat{u}_{i, t-2}+\rho_{3} \hat{u}_{i, t-3}+v_{i, t},
\end{aligned}
$$

where $\mathbf{x}_{\mathbf{t}}$ is the $t$-th observation of the vector of regressors, $\hat{u}_{i}$ is the error term associated with estimation of the $i$-th equation and $v_{i}$ is assumed to have a normal distribution with a zero mean and constant variance. The average number of parameters in each estimated equation is used to calculate the $F$ statistic for the tests. The tests are performed for each equation and jointly for the estimated demand system. The single-equation tests are only strictly relevant in a single- equation framework, and the results can only be interpreted as indicators of autocorrelation in a system context.

\section{Estimation results}

\section{Aggregate model}

Expenditure, advertising, and uncompensated price elasticities for non-alcoholic beverage demand are reported in Table 1. Of particular interest is the response to advertising. No significant response to advertising is found in the first stage. This result indicates that non-alcoholic beverage advertising has been unsuccessful in increasing the overall market size for non-alcoholic beverages. Kinnucan et al. (2001) found a corresponding result for the US. The expenditure elasticity is 0.26 and the own-price elasticity is -0.48 . None of the cross-price elasticities is statistically significant at the 5\% level. The trend is not significant. As expected, there is a significant positive seasonal effect $\left(D_{2}\right)$ during May to August. The $R^{2}$ value shows that the model explains 75 percent of the variation in the aggregate demand for non-alcoholic beverages.

\section{Autocorrelation in the AID model}

The $P$ values of the Breusch-Godfrey tests (9) for autocorrelation are shown in Table 2. A $P$

\begin{tabular}{|c|c|c|c|c|c|}
\hline \multicolumn{6}{|c|}{ Elasticities } \\
\hline Expenditure & Advertising & $\mathrm{P}_{\text {NON ALCOHOLIC }}$ & $\mathrm{P}_{\text {ALCOHOLIC }}$ & $\mathrm{P}_{\mathrm{FOOD}}$ & $\mathrm{P}_{\text {OTHER }}$ \\
\hline $\begin{array}{c}0.26^{*} \\
(1.97)\end{array}$ & $\begin{array}{c}0.00 \\
(0.09)\end{array}$ & $\begin{array}{l}-0.48^{*} \\
(-3.94)\end{array}$ & $\begin{array}{l}-0.10 \\
(-1.22)\end{array}$ & $\begin{array}{c}0.21 \\
(0.99)\end{array}$ & $\begin{array}{c}0.13 \\
(0.65)\end{array}$ \\
\hline Trend & $\mathrm{D}_{2}$ & $\mathrm{D}_{3}$ & $\mathrm{R}^{2}$ & DW & \\
\hline $\begin{array}{c}0.03 \\
(0.81)\end{array}$ & $\begin{array}{c}0.04 * \\
(4.13)\end{array}$ & $\begin{array}{l}-0.00 \\
(-0.09)\end{array}$ & 0.75 & 1.75 & \\
\hline
\end{tabular}

Table 1. First-stage elasticities, other parameter estimates, and test statistics ${ }^{1}$.

${ }^{1}$ In parentheses, $t$ ratios. A single asterisk indicates significance at the $5 \%$ level. 
Rickertsen, K. \& Gustavsen, G.W. Milk consumption and demand response to advertising

Table 2. Tests for autocorrelation, $\mathrm{P}$ values ${ }^{1}$.

\begin{tabular}{lcccc}
\hline & System & Whole milk & Cold drinks & Hot drinks \\
\hline AR(1) & & & & \\
Level & 0.00 & 0.00 & 0.83 & 0.91 \\
1st difference & 0.00 & 0.45 & 0.00 & 0.00 \\
3rd difference & 0.00 & 0.00 & 0.09 & 0.14 \\
$r_{i j}^{*}=r_{i j}-r_{i n}$ & 0.27 & 0.38 & 0.13 & 0.07 \\
$\mathrm{AR}(3)$ & & & & 0.11 \\
$r_{i j}^{*}=r_{i j}-r_{i n}$ & 0.23 & 0.31 & 0.20 & 0.11 \\
\hline
\end{tabular}

${ }^{1}$ Note: $\alpha_{0}$ is fixed in these tests.

value shows the lowest significance level at which the null hypothesis of no autocorrelation can be rejected. It is rejected at the $5 \%$ level if the $P$ value is less than 0.05 .

When our model was estimated on level form, we found first-order autocorrelation, $\operatorname{AR}(1)$, in the whole milk equation as well as in the system. First, we tried to remove the autocorrelation by estimating the model on first- and thirddifference form. Third differencing did not change the pattern of autocorrelation. On the other hand, first differencing quite successfully removed $\mathrm{AR}(1)$ in the whole milk equation. However, autocorrelation was introduced into the other two equations and did not disappear from the system.

Given these results, we followed Piggott et al. (1996) and considered a more general correction for autocorrelation. We assumed the vector of errors in our estimated system was determined by $\mathbf{u}_{\mathbf{t}}=\mathbf{R} \mathbf{u}_{\mathbf{t}-\mathbf{1}}+\mathbf{v}_{\mathbf{t}}$ where the $\mathbf{v}_{\mathbf{t}} \mathrm{s}$ are independent $\mathrm{N}(0, \Sigma)$ random vectors, and $\mathbf{R}$ is an $n$ by $n$ matrix of unknown parameters. When this assumption is used, adding up has typically been imposed by forcing $\mathbf{R}$ to be diagonal, with the

Table 3. Results of Wald tests at stage two.

\begin{tabular}{lrcc}
\hline Restrictions & \multicolumn{1}{c}{$\chi^{2}$} & \# of rest. & P value \\
\hline No advertising effects & 33.94 & 9 & 0.00 \\
No trend effects & 33.10 & 3 & 0.00 \\
No seasonal effects & 162.97 & 6 & 0.00 \\
No low fat effects & 210.91 & 6 & 0.00 \\
\hline
\end{tabular}

diagonal elements, $r_{i i}$, restricted to be the same for each equation. However, our previous test results indicate that it is unlikely that the diagonal elements are identical. Consequently, we relaxed this assumption and used the full R-matrix allowing that the off-diagonal elements are non-zero and the diagonal elements are different. Berndt and Savin (1975) showed that maximum-likelihood estimation of such a system satisfies invariance provided the $\mathbf{R}$-matrix is appropriately restricted. We followed Piggott et al. (1996) and restricted the $\mathbf{R}$-matrix such that $\boldsymbol{l}^{\prime} \mathbf{R} *$ $=0$ where $\mathbf{R}^{*}$ is an $n$ by $(n-1)$ matrix with elements $r_{i j}{ }^{*}=r_{i j}-r_{i n}$. Under the assumption that the $\mathbf{v}_{\mathbf{t}} \mathrm{s}$ are normally distributed, our results from the non-linear iterative seemingly unrelated regressions are equivalent to the maximum-likelihood estimates (Berndt and Savin 1975). This correction for autocorrelation was quite successful in removing the first-order autocorrelation. Thirdorder autocorrelation was also rejected and the remaining results were obtained within this corrected model.

\section{Specification tests}

The $\chi^{2}$ values, the number of restrictions for each null hypothesis, and the $P$ values of Wald tests, concerning hypotheses of no advertising, no trend, no seasonal, and no low fat effects, are presented in Table 3. All these hypotheses are rejected at the $5 \%$ level of significance. The rejection of no advertising effects demonstrates 
Vol. 11 (2002): 13-24.

that advertising indeed has an effect on the expenditure shares in the second stage.

\section{Elasticities and the demand response to advertising}

The estimated parameters are presented in Appendix 2 . There is a significant negative trend against whole milk. This trend increased after the introduction of low fat milk in 1985. There is also a significant and positive trend in favor of cold drinks and several significant seasonal effects.

Table 4 reports uncompensated price, advertising, and total expenditure $(E)$ elasticities. The elasticities are calculated at the mean values of the variables. Advertising for fluid milk has a significant and positive effect on whole milk demand and a significant and negative effect on the demand for lower fat milk; i.e., the advertising activities apparently delayed the transition from whole to lower fat milk. The elasticities indicate that a 20 percent increase in advertising for fluid milk has increased the sale of whole milk by approximately 1 percent and reduced the sales of lower fat milk by approximately 1.4 percent. Since the average annual per capita sales of whole and lower fat milk were 95 and 59 liters, respectively, the net effect of advertising on the total demand for fluid milk is low. The ownadvertising elasticities for cold and hot drinks are positive but not significantly different from zero.

Using the numbers in Table 4, we calculated the share weighted own-advertising elasticity for the combined fluid milk group to be 0.0008 . This low value compares reasonably well with Goddard et al.'s (1992) estimate for Canada and Kinnucan et al.'s (2001) estimate for the US, which also were found using demand systems. The other own-advertising elasticities reported in Table 5 were found by single-equation methods and they are in most cases substantially higher indicating that single-equation models may overstate the effects of advertising.
An advertising elasticity of 0.0008 suggests that additional advertising would not have been profitable. For example, in 1995 the total domestic consumption of fluid milk ( $Q_{2}$ in Fig. 3$)$ was 622 million liters, the consumer price $\left(P_{2}\right.$ in Fig. 3) approximately NOK 6.00 per liter, and the advertising expenditures approximately NOK 20 million. As argued above, the consumer price is set by the government and fixed and there are no induced price effects of milk advertising. Furthermore, as a first approximation, we set the world market price ( $P_{1}$ in Fig. 3$)$ to zero and assume that the opportunity cost of advertising expenditure is zero. Under these assumptions, a 1 percent increase in advertising expenditures (NOK 200,000) would increase the demand for milk by about 5,000 liters with a value of NOK 30,000 resulting in a direct loss of NOK 170,000. Given a positive world market price and a positive opportunity cost the loss would be even larger.

The estimated advertising elasticities (Table 4) confirm the importance of allowing for crosscommodity advertising effects. The demand for milk is affected by advertising for cold and hot drinks and the cross-advertising elasticities are numerically high; however, there are substantial standard errors associated with them. There are significant and negative cross-advertising effects of advertising for cold and hot drinks on the demand for lower fat milk. A positive cross-advertising elasticity of advertising for hot drinks on the demand for whole milk is also found. Similar and rather surprising positive cross effects were also found in Goddard et al. (1992) and Kinnucan et al. (2001). The effects of milk advertising on the demand for other beverages are insignificant.

The conditional own-price elasticities are, as expected, negative. They are also significantly different from zero, with the exception of whole milk. The numerical values are around -0.5 for the other groups of beverages, indicating priceinelastic demand. Most of the cross-price elasticities are significant and we have gross substitutes as well as gross complements. The compensated elasticities, which are not presented in 
Rickertsen, K. \& Gustavsen, G.W. Milk consumption and demand response to advertising

Table 4. Uncompensated price, advertising, and total expenditure elasticities. Mean shares and goodness of fit values ${ }^{1}$.

\begin{tabular}{|c|c|c|c|c|c|c|c|c|c|c|}
\hline & \multicolumn{4}{|c|}{ Uncompensated price } & \multicolumn{3}{|c|}{ Advertising } & \multirow[b]{2}{*}{ E } & \multirow[b]{2}{*}{$\mathrm{w}$} & \multirow[b]{2}{*}{$\mathrm{R}^{2}$} \\
\hline & 1 & 2 & 3 & 4 & 1 and 2 & 3 & 4 & & & \\
\hline 1: Whole milk & $\begin{array}{l}-0.14 \\
(-1.37)\end{array}$ & $\begin{array}{c}0.29 * \\
(4.35)\end{array}$ & $\begin{array}{c}0.21^{*} \\
(2.09)\end{array}$ & $\begin{array}{c}0.15^{*} \\
(2.71)\end{array}$ & $\begin{array}{c}0.05 * \\
(2.36)\end{array}$ & $\begin{array}{c}0.09 \\
(1.95)\end{array}$ & $\begin{array}{c}0.28 * \\
(3.79)\end{array}$ & $\begin{array}{l}-0.51^{*} \\
(-2.73)\end{array}$ & 0.23 & 0.98 \\
\hline 2: Lower fat milk & $\begin{array}{c}-0.02 \\
(-0.17)\end{array}$ & $\begin{array}{c}-0.68^{*} \\
(-4.52)\end{array}$ & $\begin{array}{c}-0.40 \\
(-1.93)\end{array}$ & $\begin{array}{c}-0.26^{*} \\
(-3.11)\end{array}$ & $\begin{array}{c}-0.07 * \\
(-1.99)\end{array}$ & $\begin{array}{c}-0.25^{*} \\
(-2.51)\end{array}$ & $\begin{array}{c}-0.35^{*} \\
(-2.87)\end{array}$ & $\begin{array}{c}1.36^{*} \\
(7.24)\end{array}$ & 0.16 & 0.99 \\
\hline 3: Cold drinks & $\begin{array}{l}-0.34 * \\
(-6.38)\end{array}$ & $\begin{array}{l}-0.21 * \\
(-2.53)\end{array}$ & $\begin{array}{c}-0.59^{*} \\
(-5.24)\end{array}$ & $\begin{array}{c}-0.40 * \\
(-8.01)\end{array}$ & $\begin{array}{c}-0.01 \\
(-0.78)\end{array}$ & $\begin{array}{c}0.11 \\
(1.91)\end{array}$ & $\begin{array}{l}-0.09 \\
(-1.21)\end{array}$ & $\begin{array}{c}1.56^{*} \\
(14.29)\end{array}$ & 0.34 & 0.91 \\
\hline 4: Hot drinks & $\begin{array}{c}-0.31 * \\
(-5.74)\end{array}$ & $\begin{array}{l}-0.16^{*} \\
(-3.14)\end{array}$ & $\begin{array}{c}-0.47^{*} \\
(-5.92)\end{array}$ & $\begin{array}{c}-0.45^{*} \\
(-7.83)\end{array}$ & $\begin{array}{c}0.02 \\
(1.08)\end{array}$ & $\begin{array}{c}-0.08 \\
(-1.12)\end{array}$ & $\begin{array}{c}0.09 \\
(0.90)\end{array}$ & $\begin{array}{r}1.40 * \\
(10.07)\end{array}$ & 0.26 & 0.97 \\
\hline
\end{tabular}

${ }^{1}$ A single asterisk indicates significance at the 5\% level. $t$ ratios in parentheses.

Table 5. Some estimated advertising elasticities for fluid milk.

\begin{tabular}{llll}
\hline Reference & Elasticity & Location & Data period \\
\hline Kinnucan and Belleza (1991) & 0.044 & Ontario, Canada & $1973-1984$ \\
Goddard et al. (1992) & 0.002 & Ontario, Canada & $1971-1984$ \\
Kinnucan and Venkateswaran (1994) & $0.000-0.031$ & Ontario, Canada & $1973-1987$ \\
Reberte et al. (1996) & $0.000-0.055$ & New York & $1986-1992$ \\
Lenz et al. (1998) & $0.014-0.088$ & New York & $1986-1995$ \\
Kamp and Kaiser (1999) & $0.049-0.067$ & New York & $1986-1995$ \\
Tomek and Kaiser (1999) & 0.029 & United States & $1976-1997$ \\
Chung and Kaiser (1999) & 0.058 & New York & $1986-1995$ \\
Kinnucan et al. (2001) & 0.003 & United States & $1970-1994$ \\
The present study & 0.001 & Norway & $1975-1995$ \\
\hline
\end{tabular}

the table, show that none of the beverages are net complements. The expenditure elasticities are significant and positive, except for whole milk, which appears to be an inferior good within the second stage.

\section{Conclusions}

Aggregate demand for non-alcoholic beverages is unresponsive to advertising expenditures, suggesting that advertising has not increased the market size for non-alcoholic beverages. The allocation of beverage expenditures to the various non-alcoholic beverages is, however, affected. There are different effects of generic advertising on the demand for whole and lower fat milk, indicating that these beverages are better treated separately. Advertising for fluid milk has a significant and positive effect on whole milk's expenditure share and a significant and negative effect on the expenditure share of lower fat milk; i.e., the generic advertising activities have probably delayed the transition from whole to lower fat milk. The net effect of milk advertising on the total fluid milk demand is low with an ownadvertising elasticity for the combined fluid milk group of 0.0008 . Given fixed prices, increased advertising will not be profitable for the producers.

We found several cross-commodity effects. There are significant and negative cross-advertising effects of advertising for cold and hot drinks on the demand for lower fat milk. These results demonstrate that successful advertising for products such as carbonated soft drinks may 
Vol. 11 (2002): 13-24.

have a large impact on fluid milk demand. The positive effect of advertising for hot drinks on the whole milk demand indicates that there also may be complementary relationships in advertising. The effects of milk advertising on the demand for other beverages are insignificant. The results demonstrate that a demand system approach is useful for studying the effects of generic fluid milk advertising.

Acknowledgements. Thanks to one anonymous referee for helpful comments. The research was sponsored by the Research Council of Norway, grant no. 109538/110 and grant no. $134018 / 110$

\section{References}

Berndt, E.R. \& Savin, N.E. 1975. Evaluation and hypothesis testing in singular equation systems with autoregressive disturbances. Econometrica 32: 937-957.

Bronsard, C. \& Salvas-Bronsard, L. 1984. On price exogeneity in complete demand systems. Journal of Econometrics 24: 235-247.

Carpentier, A. \& Guyomard, H. 2001. Unconditional elasticities in two-stage demand systems: an approximate solution. American Journal of Agricultural Economics 83: 222-229.

Chung, C. \& Kaiser, H.M. 1999. Measurement of advertising effectiveness using alternative measures of advertising exposure. Agribusiness 15: 525-537.

Deaton, A. \& Muellbauer, J. 1980. An almost ideal demand system. The American Economic Review 70: 312-326.

Forker, O.D. \& Ward, R.W. 1993. Commodity advertising: The economics and measurement of generic programs. New York: Lexington Books. 294 p.

Goddard, E.W. \& Amuah, A.K. 1989. The demand for Canadian fats and oils: a case study of advertising effectiveness. American Journal of Agricultural Economics 71: 741-749.

Goddard, E.W., Kinnucan, H.W., Tielu, A. \& Belleza, E. 1992. Advertising fluid milk in Ontario. In: Johnson, S.R. et al. (eds.). Market demand for dairy products. Ames: lowa State University Press. p. 274-288.

Johnson, S.R., Stonehouse, D.P. \& Hassan, Z.A. 1992. Market demand for dairy products. Ames: lowa State University Press. 310 p.

Kaiser, H.M. 1997. Impact of national generic dairy advertising on dairy markets, 1984-1995. Journal of Agricultural and Applied Economics 29, 2: 303-313.

Kaiser, H.M. \& Reberte, J.C. 1996. Impact of generic advertising for fluid milk on demand for whole, lowfat, and skim milks. Journal of Dairy Science 79: 2284-2291.

Kamp, P.R.V. \& Kaiser, H.M. 1999. Irreversibility in advertising-demand response functions: an application to milk. American Journal of Agricultural Economics 81: 385-396.

Kinnucan, H.W. 1999. Optimal generic advertising decisions in supply-managed industries: clarification and some further results. Canadian Journal of Agricultur- al Economics 47: 57-66.

Kinnucan, H.W. \& Belleza, E. 1991. Advertising evaluation and measurement error: the case of fluid milk in Ontario. Canadian Journal of Agricultural Economics 39: 293-297.

Kinnucan, H.W., Miao, Y., Xiao, H. \& Kaiser, H.M. 2001. Effects of advertising on U.S. non-alcoholic beverage demand: evidence from a two-stage Rotterdam model. In: Baye, M.R. \& Nelson, J.P. (eds.). Advertising and differentiated products. Amsterdam: JAI. p. 1-29.

Kinnucan, H.W. \& Myrland, Ø. 2001. A note on measuring returns to nonprice export promotion. Agribusiness 17: 423-433.

Kinnucan, H.W. \& Venkateswaran, M. 1994. Generic advertising and the structural heterogeneity hypothesis. Canadian Journal of Agricultural Economics 42: 381-396.

Lee, J. \& Brown, M.G. 1992. Lag structures in commodity advertising research. Agribusiness 8: 143-154.

Lenz, J., Kaiser, H.M. \& Chung, C. 1998. Economic analysis of generic milk advertising impacts on markets in New York State. Agribusiness 14: 73-83.

Moschini, G. 1995. Units of measurement and the Stone index in demand system estimation. American Journal of Agricultural Economics 77: 63-68.

Piggott, N.E., Chalfant, J.A., Alston, J.M. \& Griffith, G.R. 1996. Demand response to advertising in the Australian meat industry. American Journal of Agricultural Economics 78: 268-279.

Pritchett, J.G., Liu, D.J. \& Kaiser, H.M. 1998. Optimal choice of generic milk advertising expenditures by media outlet. Journal of Agricultural and Resource Economics 23: 155-169.

Putnam, J.J. \& Allshouse, J.E. 1997. Food consumption, prices, and expenditures, 1970-95. ERS Statistical Bulletin No. 939, USDA.

Putnam, J.J. \& Allshouse, J. 1998. U.S. per capita food supply trends. Food Review 21, 3: 2-11.

Reberte, C., Kaiser, H.M., Lenz, J.E. \& Forker, O. 1996. Generic advertising wearout: The case of the New York City fluid milk campaign. Journal of Agricultural and Resource Economics 21: 199-209. 
Rickertsen, K. \& Gustavsen, G.W. Milk consumption and demand response to advertising

Richards, T.J., Van Ispelen, P. \& Kagan, A. 1997. A twostage analysis of the effectiveness of promotion programs for U.S. apples. American Journal of Agricultural Economics 79: 825-837.

Suzuki, N. \& Kaiser, H.M. 1997. Imperfect competition models and commodity promotion evaluation: the case of U.S. generic milk advertising. Journal of $\mathrm{Ag}$ ricultural and Applied Economics 29: 315-325.
Suzuki, N., Kaiser, H.M., Lenz, J.E., Kobayashi, K. \& Forker, O. 1994. Evaluating generic milk promotion effectiveness with an imperfect competition model. American Journal of Agricultural Economics 76: 296302.

Tomek, W.G. \& Kaiser, H.M. 1999. On improving econometric analyses of generic advertising impacts. Agribusiness 15: 485-500. 
Appendix 1

\section{Derivation of advertising elasticities}

For simplicity, we neglect the dummy variables and the trend and re-write equation (7) as

$$
\alpha_{i}=\alpha_{i 0}+\sum_{j=1}^{n} \phi_{i j}\left(\ln a d v_{j}-\sum_{j=1}^{n} w_{j} \ln p_{j}\right)
$$

Substituting equations (5) and (A1) into equation (4) yields

(A2)

$$
\begin{aligned}
w_{i} & =\alpha_{i 0}+\sum_{j=1}^{n} \phi_{i j}\left(\ln a d v_{j}-\sum_{j=1}^{n} w_{j} \ln p_{j}\right)+\sum_{j=1}^{n} \gamma_{i j} \ln p_{j}+\beta_{i} \ln x-\beta_{i} \alpha_{0}-\beta_{i} \sum_{k=1}^{n} \alpha_{k 0} \ln p_{k} \\
& -\beta_{i} \sum_{k=1}^{n} \sum_{j=1}^{n} \phi_{k j}\left(\ln a d v_{j}-\sum_{j=1}^{n} w_{j} \ln p_{j}\right) \ln p_{k}-\frac{1}{2} \beta_{i} \sum_{k=1}^{n} \sum_{j=1}^{n} \gamma_{k j} \ln p_{k} \ln p_{j} .
\end{aligned}
$$

By definition $q_{i}=w_{i} x / p_{i}$ where $w_{i}$ is given by equation (A2) and the other variables are as previously defined. Using the chain rule, the advertising elasticities, $a_{i j}$, are calculated as

$$
a_{i j}=\left(\frac{\partial q_{i}}{\partial \ln a d v_{j}} \cdot \frac{\partial \ln a d v_{j}}{\partial a d v_{j}} \cdot \frac{a d v_{j}}{q_{i}}\right)=\frac{x}{p_{i}}\left(\phi_{i j}-\beta \sum_{k=1}^{n} \phi_{k j} \ln p_{k}\right) \frac{1}{a d v_{j}} \frac{a d v_{j}}{q_{i}}
$$

or equation (8). 
Appendix 2

Estimated parameters ${ }^{1}$.

\begin{tabular}{|c|c|c|c|c|}
\hline & & $\begin{array}{l}\text { Whole milk } \\
\qquad(\mathrm{i}=1)\end{array}$ & $\begin{array}{l}\text { Cold drinks } \\
\qquad(\mathrm{i}=3)\end{array}$ & $\begin{array}{l}\text { Hot drinks } \\
\quad(\mathrm{i}=4)\end{array}$ \\
\hline$\alpha_{0}$ & $\begin{array}{l}-4.815^{*} \\
(-2.58)\end{array}$ & & & \\
\hline$\alpha_{i 0}$ & & $\begin{array}{l}1.882^{*} \\
(3.72)\end{array}$ & $\begin{array}{l}-0.796 \\
(-1.89)\end{array}$ & $\begin{array}{l}-0.197 \\
(-1.21)\end{array}$ \\
\hline$\alpha_{i 1}$ & & $\begin{array}{l}0.186^{*} \\
(6.04)\end{array}$ & $\begin{array}{c}0.021 \\
(0.36)\end{array}$ & $\begin{array}{c}0.003 \\
(0.06)\end{array}$ \\
\hline$\alpha_{i 2}$ & & $\begin{array}{l}-0.004^{*} \\
(-5.49)\end{array}$ & $\begin{array}{l}0.004 * \\
(3.59)\end{array}$ & $\begin{array}{l}-0.002 \\
(-1.93)\end{array}$ \\
\hline$\alpha_{i 3}$ & & $\begin{array}{l}-0.006^{*} \\
(-8.20)\end{array}$ & $\begin{array}{l}-0.000 \\
(-0.26)\end{array}$ & $\begin{array}{l}-0.000 \\
(-0.46)\end{array}$ \\
\hline$\psi_{i 2}$ & & $\begin{array}{c}-0.002 \\
(-0.60)\end{array}$ & $\begin{array}{l}0.042 * \\
(6.35)\end{array}$ & $\begin{array}{l}-0.018^{*} \\
(-3.36)\end{array}$ \\
\hline$\psi_{i 3}$ & & $\begin{array}{c}0.014^{*} \\
(3.79)\end{array}$ & $\begin{array}{l}-0.001 \\
(-0.09)\end{array}$ & $\begin{array}{c}0.002 \\
(0.32)\end{array}$ \\
\hline$\gamma_{i 1}$ & & $\begin{array}{l}-0.574 * \\
(-3.47)\end{array}$ & - & - \\
\hline$\gamma_{i 3}$ & & $\begin{array}{l}0.302^{*} \\
(2.18)\end{array}$ & $\begin{array}{c}0.003 \\
(0.03)\end{array}$ & - \\
\hline$\gamma_{i 4}$ & & $\begin{array}{l}0.147 * \\
(3.44)\end{array}$ & $\begin{array}{l}-0.199 * \\
(-7.93)\end{array}$ & $\begin{array}{l}0.111 * \\
(3.81)\end{array}$ \\
\hline$\phi_{i 1}$ & & $\begin{array}{l}0.011^{*} \\
(2.36)\end{array}$ & $\begin{array}{l}-0.004 \\
(-0.76)\end{array}$ & $\begin{array}{r}0.005 \\
(1.08)\end{array}$ \\
\hline$\phi_{i 3}$ & & $\begin{array}{c}0.016 \\
(1.43)\end{array}$ & $\begin{array}{c}0.042 \\
(1.95)\end{array}$ & $\begin{array}{l}-0.019 \\
(-1.06)\end{array}$ \\
\hline$\phi_{i 4}$ & & $\begin{array}{l}0.070^{*} \\
(3.91)\end{array}$ & $\begin{array}{c}-0.035 \\
(-1.24)\end{array}$ & $\begin{array}{r}0.022 \\
(0.87)\end{array}$ \\
\hline$\beta_{i}$ & & $\begin{array}{l}-0.354 * \\
(-8.08)\end{array}$ & $\begin{array}{l}0.191 * \\
(5.12)\end{array}$ & $\begin{array}{l}0.104^{*} \\
(2.86)\end{array}$ \\
\hline$\rho_{i 1}$ & & $\begin{array}{l}0.722 * \\
(7.31)\end{array}$ & $\begin{array}{l}-0.028 \\
(-0.25)\end{array}$ & $\begin{array}{c}0.178 \\
(1.91)\end{array}$ \\
\hline$\rho_{i 3}$ & & $\begin{array}{l}0.509^{*} \\
(2.13)\end{array}$ & $\begin{array}{r}0.517 \\
(1.74)\end{array}$ & $\begin{array}{l}-0.417 \\
(-1.50)\end{array}$ \\
\hline$\rho_{i 4}$ & & $\begin{array}{c}0.515 \\
(1.91)\end{array}$ & $\begin{array}{l}0.763 * \\
(2.08)\end{array}$ & $\begin{array}{l}-0.538 \\
(-1.66)\end{array}$ \\
\hline
\end{tabular}

${ }^{1} t$ ratios are in parentheses. A single asterisk indicates significance at the $5 \%$ level. The parameters for the equation lower fat milk are not estimated $(i=2)$. 